\title{
Globalisation, the sex industry, and health
}

\section{$\mathrm{H}$ Ward, SO Aral}

\section{Opportunities and demand for commercial sex are expanding}

G lobal changes in migration, health, employment, and public policy are having a major impact on the sex industry. As editors of this themed issue on sex work have put together papers to document some of these changes, revisit the epidemiological and social understanding of the role of sex work in relation to sexually transmitted infections, and assess interventions that can reduce the burden of disease and of stigma on participants in the industry.

Major drivers of change in the sex industry are economic, demographic, ideological, and technological. Globalisation is the umbrella term used to express many of these changes, which include increased economic interdependence of different countries through trade, the extension of the world market to areas of the world previously isolated, increased movement of people and of capital, and the rapid spread of new technologies and media across wide sections of the globe.

Each of these aspects has had an impact on the sex industry. ${ }^{1}$ For example, countries of the former Soviet Union have seen a massive economic transition with an increase in unemployment and radical restructuring of employment. ${ }^{23}$ More people are seeking paid work and many cannot find it in the formal sector and look to alternatives, one of which is the sex industry. Some people move to urban centres, others to different countries in the hope of finding a better living. Some individuals, mainly women, are coerced into migrating for sex work or other forms of informal or unregulated labour. It is difficult to quantify the actual numbers of people selling sex but there are many reports of a widespread increase in numbers of sex workers. ${ }^{5}$

This greater potential supply of sex workers seems to be matched by increased demand in many parts of the world. In the United Kingdom, for example, the proportion of men who reported paying for sex doubled in the decade from 1990 to 2000. Global estimates again are difficult to provide but one review found that in half of the countries studied at least $9 \%$ of men reported paying for sex in the previous 12 months. ${ }^{8}$ Opportunities and demand for commercial sex are likely to expand as divorce rates rise, people travel more, and in many countries adults spend a greater proportion of their lives living alone. ${ }^{9}$

These demographic changes link to other economic factors, the most important being poverty and inequality. Women earn less than men, foreigners earn less than locals, young workers earn less than older people. These inequalities mean that some people are in much greater, often desperate, need of money while others have growing disposable incomes. In many western countries such as the United States and the United Kingdom such unequal distribution of wealth has led to an increase in many personal services, including domestic work, child care, etc, where one individual earns enough to employ another person. ${ }^{10}$ The inequalities also lead to relative deprivations; individuals who are not deprived in the absolute sense of the term may feel deprived in comparison with the very rich and seek to supplement their income through sex work.

\section{...the organisation and conditions of sex work are highly diverse}

There are many ideological influences on the sex industry and these vary by country and culture, but the growth of sex as a commodity is reflected in the increased use of sexual images in advertising, the rapid growth of the adult entertainment industry, virtual and real, and the widespread availability of pornography on the internet. This growing market in sex continues despite the actions of many governments, faiths, and social movements to try and regulate or abolish it. It appears that stressing the sanctity of sexual relations within marriage is no match for the advertising power of business.

These major changes appear to have led to an increase in the size of the sex industry. Alongside this has been a transformation in its organisation.
Communication technologies allow sex work businesses to advertise on the internet, no longer bounded by national borders in terms of advertising or indeed regulations. Internet enabled mobile phones mean that clients can find a sex worker almost anywhere in the world instantly, and they can also read online reviews of individual sex workers that are regularly posted on punters' websites. Elsewhere, sex workers are based in more traditional brothels and bars, but may also come into contact with a wider range of clients owing to the expansion in international travel for work and recreation.

Against this changing backdrop, regulations have also been evolving. ${ }^{11}$ In some countries, including New Zealand, the Netherlands, and Australia, aspects of sex work have been decriminalised, while in others-for example, Sweden, men who pay for sex have been criminalised. Increasing concern over international mobility of sex workers, whether voluntary or coerced in the form of trafficking, has led to a raft of new legislation and increased surveillance of the industry.

These broad changes have had different effects. In the United Kingdom and much of western Europe there has been a rapid increase in migrants, women and men, selling sex. ${ }^{12}{ }^{13}$ This has altered some of the previous structures of the sex industry, with a shift to less visible forms of work to reduce the risk of arrest and deportation. In London, sex workers now work mainly from private addresses, although these are still part of a network with key people, managers or "maids," facilitating negotiations and providing health advice for new workers. ${ }^{14}$

In Russia many sex workers are migrants from other parts of the Russian Federation. ${ }^{15}$ It is not new for sex workers to move location in order to work, but the scale and range of migration presents challenges for the workers themselves. Working in a strange environment, often not knowing the local language, being unaware of their rights, they are very vulnerable to exploitation and abuse. Old norms of solidarity and support between sex workers may be broken up, and the peer values, including those that determine health and safety norms, may be disrupted with this mobility. In a different way, new technology has also disrupted previous norms of organisation. The ubiquitous mobile phone and internet advertising can also break up communities of workers into isolated individuals. Another effect of the broad changes involves the socioeconomic background composition of sex workers. Men and women who exchange sex for 
money come from increasingly diverse backgrounds; some are from high educational and socioeconomic status brackets. ${ }^{16}{ }^{17}$

Sex workers have always been at risk of sexually transmitted infections (STI), and are frequent targets of control programmes. Some of these interventions have been helpful in providing resources and health care, but many actually reinforce stigma and a culture of blaming sex workers for spreading disease. There has been considerable research on sex workers over the two decades since HIV was recognised as an STI, and this body of work shows that sex work is diverse, and that simple models suggesting that it has a central role in the spread of disease are false. In many countries of the global north, many, but not all, sex workers are at a relatively low risk of HIV. They work carefully, professionally, and manage to have multiple sexual partners without acquiring HIV or other STI. In contrast, in many countries of the global south, some, but not all, sex workers are at high risk of acquiring HIV. Thus, a unified approach to sex workers in the context of STI and HIV prevention would be unwise. Interventions should be based on good information about the local organisation of the sex industry, the health risks involved, and the input from sex workers about the most effective way of reaching their peers.

\section{In this issue}

In this issue of STI researchers in Estonia describe in detail the organisation of the sex industry, demonstrating that it has become both very varied, including migrants and locals, part timers, and full timers, and geographically widespread. ${ }^{18}$ This poses challenges for interventions since many sex workers are invisible.

Their work underlines the need for local understanding of the sex industry and other risk contexts. At the most basic level commercial is not always clearly distinct from other forms of sexual contact, and the counterposition of high risk (sex work) and general population (non-commercial) can be counterproductive, reinforcing an idea that the exchange of cash is more likely to transmit infection than the exchange of love. For many people struggling to survive, the borderline between sex for convenience and for commerce is not clear. Jessica Edwards and colleagues report in this issue on factors predicting exchange of sex for drugs or money among adolescents in the United States. ${ }^{19}$ They found that $3.5 \%$ of adolescents had exchanged sex for money, two thirds of these being boys. The adolescents reported a median of one exchange each, indicating that this was not "sex work" as such, but the activity was associated with drug use, running away from home, other sexual risk behaviours, and higher self reported HIV and STI. The dividing line between trading and other sexual contact may be blurred, and therefore harm reduction programmes should address a range of transactional sex and not just the organised sex industry.

Sethi and colleagues provide an overview of the characteristics of men who sell sex, a group with very little research to date. ${ }^{20}$ Over a period of 10 years the men using a specialist health project became more diverse, with fewer UK born men, and an increase in men who identified as heterosexual but who nevertheless sold sex to other men.

Groom and Nandwani ${ }^{21}$ reviewed notes from the $10 \%$ of men at their sexually transmitted diseases clinic who reported paying for sex. They found a wide range of patterns of sex work contact by men from all social groups, but note that men appear to either buy sex locally or overseas, but rarely both. The association of commercial sex with mobile men has been well described, and has been thought to play a part in the geographic dispersion of HIV.

Morris and Ferguson explore the continued contribution of truck routes in Kenya and Uganda to the HIV epidemic. ${ }^{22}$ Using a simple transmission model with parameters derived from empirical research at "hot spots" along the trans-Africa highway, they estimated that preventive interventions for people engaged in transactional sex remain important and could prevent around two thirds of 3000 to 4000 new HIV infections each year. The authors conclude that targeted interventions retain their validity even in the context of a generalised HIV epidemic, an issue that has been debated in recent years. Interventions targeting sex workers are often assumed to be an efficient way of controlling early stages of an epidemic, but once the infection is widespread they are considered less important. In reality sex workers and their clients remain at risk of acquiring and transmitting infections through all phases of STI epidemics, and programmes should continue to support targeted interventions to reduce these risks.

One extensive programme that includes sex worker interventions is the Avahan project in India. The initiative explicitly aims to reduce HIV in sex workers and clients in order to limit HIV transmission in the general population. The fieldwork for this project is ongoing, but in this issue of STI researchers report results of early modelling projections. ${ }^{23}$ They estimate the proportion of HIV infections likely to be prevented, and conclude that the impact is highly dependent on achieving good coverage of the target population. Steen and colleagues take this issue of coverage further in an article looking at the initial results from Avahan. They explore the challenge of delivering interventions on a scale and of a quality sufficient to be effective. In the first 2 years they estimate that around $70 \%$ of sex workers have been contacted by peer educators and $41 \%$ have attended a clinic at least once. ${ }^{24}$ This project has considerable resources, from the Bill and Melinda Gates Foundation, to cover six states in India, and demonstrates the scale of the challenge for governments in delivering such interventions in the real world. The authors stress the importance of involving sex workers at all stage of the intervention.

\section{Targeting should complement population-wide initiatives}

Targeted interventions often appeal to policy makers as they sound more achievable and less expensive than addressing the whole population. In reality targeting should complement population-wide initiatives, and both must be sustained. Sex workers in the Philippines were contacted through outreach, given a single presumptive treatment for chlamydia and gonorrhoea, and provided with improved prevention and screening services. ${ }^{25}$ Following the presumptive treatment the prevalence of these two infections declined in the sex workers and clients, but then rose again. If risk networks remain in place then this is inevitable, showing the need for sustained interventions that combine high quality screening and treatment with health promotion for the women and men involved. Schwandt and colleagues also point out that health promotion must include discussion of specific behaviours, such as anal sex and dry sex, which they identify as particularly risky practices. ${ }^{26}$

The development of female controlled methods of HIV prevention is a global priority, with research into some promising microbicides. ${ }^{27}$ In advance of these becoming available, researchers in Kenya studied the impact of introducing the female condom to sex workers, and found a small reduction in unprotected sex, but report that it was mostly used as a substitute for the male condom, at much higher cost. ${ }^{28}$ Further advances in female controlled methods are anticipated with ongoing trials of various microbicides, which could be used in addition to the male condom and potentially in situations where the man refuses protection. 
Another technological development that should improve health of sex workers is the revolution in diagnostics. Rapid, point of care tests are available for several STI already, but many have a poor sensitivity and are too expensive for widespread introduction. The lack of cheap diagnostic tools is a major obstacle to scaling up effective interventions for sex workers. In many resource-poor settings, laboratory diagnostics are not available, and women are managed using a syndromic approach, which is known to be problematic because common syndromes in women are neither specific nor sensitive measures of infection. Vickerman and colleagues have modelled the cost effectiveness of rapid tests, and looked at introducing them in clinical services for sex workers in Cotonou, Benin..$^{29}$ They estimate that a gonorrhoea and chlamydia test with a relatively low sensitivity $(70-80 \%)$ and specificity (95\%) could reduce overtreatment by almost a third, and avert almost half of the bacterial and HIV infections. At a cost of \$1 per test the cost per HIV infection averted would be between $\$ 58$ and $\$ 81$, a good investment by most healthcare standards.

Taken together these papers provide an outline of the kind of interventions that can improve health for sex workers, and that need to be rolled out Successful programmes are based on sound knowledge of the local sex industry and context, include sex workers as advisers, combine outreach, health promotion and quality STI diagnostic and treatment services. These need to be of sufficient scale, quality and sustained in order to control existing STI and HIV epidemics, and to prevent future ones from becoming established.

Two final papers, one from London and one from San Francisco, report a more holistic approach to health of sex workers. In London women were followed up over a longer period of time, up to 15 years; and many were still in the sex industry and their health problems were diverse. ${ }^{30}$ Many had mental health problems, addictions, and longterm sequelae of STI. In San Francisco an innovative healthcare programme for sex workers was set up in 1999, on the basis that sex workers were not simply in need of STI check ups and condoms, but of a range of health care. ${ }^{31}$ Cohan et al found that many sex workers never discussed their work with a healthcare provider and the most pressing problem was domestic violence.

The changes in determinants of sex work discussed earlier and the group of papers included in the current issue of STI point to a number of emerging patterns in the volume and organisation of paid for sex. Firstly, it appears that the volume of sex work is expanding. Secondly, the organisation and conditions of sex work are highly diverse. Thirdly, sex work remains an integral part of society, increasingly accepted in many parts of the world. Finally, men and women who engage in sex work come from all strata of society, which means that the interventions to improve health and control STI must be flexible and responsive. We hope the collection of articles in this special issue will stimulate further work in this domain.

Sex Transm Infect 2006;82:345-347. doi: $10.1136 /$ sti.2006.023044

\section{Authors' affiliations}

H Ward, STI Prevention and Control Research Group, Department of Infectious Disease Epidemiology, Faculty of Medicine, Imperial College London, London W2 IPG, UK S O Aral, Division of STD Prevention, Centers for Disease Control and Prevention (CDC), 1600 Clifton Road, Atlanta, GA 30333, USA

Correspondence to: Helen Ward, STI Prevention and Control Research Group, Department of Infectious Disease Epidemiology, Faculty of Medicine, Imperial College London, London W2 IPG, UK; h.ward@imperial.ac.uk

The findings and conclusions in this report are those of the author(s) and do not necessarily represent the views of the Centers for Disease Control and Prevention (CDC)

\section{REFERENCES}

1 Ward H, Day S. Sex work in context. In: Day S, Ward $\mathrm{H}$, eds. Sex work, mobility and health in Europe. London: Kegan Paul, 2004:15-33.

2 World Bank. From transition to development. A country economic memorandum for the Russian Federation, Report No 32308 RU.March, 2005.

3 Milanovic B. Income, equality and poverty during the transition from planned to market economy. Washington, DC: World Bank, 1998:41.

4 International Labor Organization. World Employment Report 2001. Geneva: ILO, 2001

5 Vandepitte J, Lyerla R, Dallabetta G, et al. Estimates of the number of female sex workers in different regions of the world. Sex Transm Infect 2006;82:iii 18-iii25.

6 Sassen S. Women's burden: counter-geographies of globalization and the feminization of survival. Nordic J International Law 2002;71:255-74.

7 Ward H, Mercer C, Wellings K, et al. Who pays for sex? An analysis of the increasing prevalence of female commercial sex contacts among men in Britain Sex Transm Infect, 2005;81:467-71.

8 Carael M, Slaymaker E, Lyerla R, et al. Clients of sex workers in different regions of the world: hard to count. Sex Transm Infect 2006:82:iii26-iii33.

9 Aral SO, Ward H. Modern day influences on sexual behaviour. Infect Dis Clin North Am 2005; 19:297-309.

10 Enrenreich B, Hochschild AR, eds. Global woman: nannies, maids, and sex workers in the new economy. New York: Metropolitan Books, 2003.
11 Visser J, Randers-Pehrson A, Day S, et al. Policies towards the sex industry in Europe: new models of control. In: Day S, Ward H, eds. Sex work, mobility and health in Europe. London: Kegan Paul, 2004:241-60.

12 Ward H, Day S, Green A, et al. Declining prevalence of STI in the London sex industry, 1985 to 2002. Sex Transm Infect 2004;80:374-9.

13 European Network for HIV/STI Prevention in Prostitution (Europap). Final Report 2004 (see www.europap. net country reports)

14 Cooper K, Day S, Green A, et al. Maids, migrants and occupational health in the London sex industry. Anthropolgy and Medicine In press.

15 Aral SO, St Lawrence JS, Tikhonova L, et al. The social organisation of commercial sex work in Moscow, Russia. Sex Transm Dis 2003;30:39-45.

16 Aral SO, St Lawrence JS. The ecology of sex work and drug use in Saratov Oblast, Russia. Sex Transm Dis 2002;29:798-805.

17 Aral SO, St Lawrence JS, Dyatlov R, et al. Commercial sex work, drug use, and sexually transmitted infections in St Petersburg, Russia. Soc Sci Med 2005;60:2181-90.

18 Aral SO, St Lawrence JS, Uusküla A. Sex work in Tallinn, Estonia: the sociospatial penetration of sex work into society. Sex Transm Infect 2006:82:348-53.

19 Edwards JM, Iritani BJ, Hallfors DD. Prevalence and correlates of exchanging sex for drugs or money among adolescents in the United States. Sex Transm Infect 2006:82:354-8.

20 Sethi G, Holden BM, Gaffney J, et al. HIV, sexually transmitted infections, and risk behaviours in male sex workers in London over a 10 year period. Sex Transm Infect 2006:82:359-63.

21 Groom T, Nandwani R. Characteristics of men who pay for sex: a UK sexual health clinic survey. Sex Transm Infect 2006;82:364-7.

22 Morris CN, Ferguson A. Estimation of the sexual transmission of HIV in Kenya and Uganda on the trans-Africa highway: the continuing role for prevention in high risk groups. Sex Transm Infect 2006;82:368-71.

23 Williams JR, Foss AM, Vickerman $\mathrm{P}$, et al. What is the achievable effectiveness of the India AIDS Initiative intervention among female sex workers under target coverage? Model projections from southern India. Sex Transm Infect 2006;82:372-80

24 Steen R, Mogasale V, Wi T, et al. Pursuing scale and quality in STI interventions with sex workers: initial results from Avahan India AIDS Initiative. Sex Transm Infect 2006:82:381-5

25 Wi T, Ramos ER, Steen R, et al. STI declines among sex workers and clients following outreach, one time presumptive treatment, and regular screening of sex workers in the Philippines. Sex Transm Infect 2006:82:386-91.

26 Schwandt M, Morris C, Ferguson A, et al. Anal and dry sex in commercial sex work, and relation to risk for sexually transmitted infections and HIV in Meru, Kenya. Sex Transm Infect 2006:82:392-6

27 Minnis AM Padian NS. Effectiveness of female controlled barrier methods in preventing sexually transmitted infections and HIV: current evidence and future research directions. Sex Transm Infect 2005:81:193-200.

28 Thomsen SC, Ombidi W, Toroitich-Ruto C, et al. A prospective study assessing the effects of introducing the female condom in a sex worker population in Mombasa, Kenya. Sex Transm Infect 2006:82:397-402

29 Vickerman P, Watts C, Peeling RW, et al. Modelling the cost effectiveness of rapid point of care diagnostic tests for the control of HIV and other sexually transmitted infections among female sex workers. Sex Transm Infect 2006;82:403-12

30 Ward H, Day S. What happens to women who sell sex? Report of a unique occupational cohort. Sex Transm Infect 2006:90:413-17.

31 Cohan D, Lutnick A, Davidson P, et al. Sex worker health: San Francisco style. Sex Transm Infect 2006:82:418-22. 